\title{
Idiopathic intracranial hypertension: adult versus pediatric patients
}

Peter KC Leung, MBBCh, Jonathan CH Ho, FRCP (Edin) FRCSEd, Simon TC Ko, FRCSEd Department of Ophthalmology, Tung Wah Eastern Hospital, Hong Kong SAR, China.

Correspondence and reprint requests:

Dr Jonathan CH Ho, Department of Ophthalmology, Tung Wah Eastern Hospital, 19 Eastern Hospital Road, Causeway Bay, Hong Kong SAR, China.

Email: mr.jonathanho@gmail.com

\begin{abstract}
Idiopathic intracranial hypertension (IIH), also known as benign intracranial hypertension or pseudotumor cerebri, is characterized by increased intracranial pressure secondary to unknown causes. IIH affects both adults and children but predominately young obese females of child-bearing age. IIH gives rise to headache, visual disturbances, and symptoms of raised intracranial pressure. The pathophysiology of IIH remains elusive; postulations include obesity-related hormonal changes, obstruction of the central venous sinus, and hereditary causes. Diagnosing IIH is based on modified Dandy criteria. Diagnosis in children is challenging as symptoms and presentations vary; atypical and delayed presentations are not uncommon. Treatment for IIH includes oral acetazolamide or lumbar puncture; surgical treatment with shunts and optic nerve sheath fenestration is reserved for complicated and recurring cases. Treatment options for children are limited and associated with considerable risks and side effects. Vision loss is debilitating and occurs in 10\% of IIH patients. A thorough and collaborative approach in managing IIH is needed. This study reviews the epidemiology, clinical presentation, diagnosis, and management of IIH in adults and pediatric patients.
\end{abstract}

Key words: Headache; Idiopathic intracranial hypertension with papilledema; Obesity; Pseudotumor cerebri

\section{Epidemiology}

Idiopathic intracranial hypertension (IIH) can occur at all stages of life irrespective of sex but has a predilection towards obese females. ${ }^{1}$ The annual incidence of $\mathrm{IIH}$ is 0.9 cases per 100,000 people and 3.5 cases per 100,000 obese females of child-bearing age. ${ }^{2}$ The incidence of IIH in Asians is lower. In a Japanese cohort, the incidence of IIH was 0.3 cases per 100,000 people per year. ${ }^{3}$ The incidence in Chinese is not well studied but is believed to be infrequent. ${ }^{4}$ Observational studies have shown a direct relationship between increased body mass index and the risk of IIH. ${ }^{5}$ The incidence is expected to increase with the global obesity epidemic. Patients with recent weight gain of $5 \%$ to $15 \%$ have a higher risk of developing IIH than those with stable weight. ${ }^{5}$ About $10 \%$ of IIH patients are men who are usually diagnosed a decade older than women. ${ }^{6}$ Black patients seem to have a worse vision prognosis than whites. It is unknown whether Asians have the same risks of developing IIH as other races. ${ }^{7,8}$

Childhood IIH occurs most frequently after puberty. ${ }^{9}$ Prepubertal IIH is uncommon and is rare in neonates and preschool children. The estimated incidence of childhood IIH is 0.8 cases per 100,000 children. In Hong Kong, the incidence was 0.78 case per $100,000 .^{10}$ These figures are probably underestimated because of selection bias and diagnostic problems. Post-pubertal IIH patients are mostly obese females, whereas pre-pubertal IIH patients are usually non-obese, with males and females equally affected..$^{11,12}$ A retrospective multicenter study of pediatric IIH using anthropometric parameters identified 3 subgroups of patients: young children (girls aged $<7$ years and boys aged $<8.5$ years) who were not overweight; early adolescents (boys and girls aged 7-12 years) who were taller and overweight; and late adolescents (boys and girls aged $\geq 12.5$ years) who were overweight. ${ }^{13}$ It is unclear whether these 3 subgroups represent natural progression of pediatric IIH or distinct subgroups of disease with different pathophysiology. The association of adiposity and increased linear growth acceleration in post-pubertal, early and late adolescent 
IIH patients echoes that of adult IIH cohorts. Contributing factors other than adiposity have yet to be determined. Nevertheless, the overall trend in childhood obesity and metabolic syndromes may increase the incidence of pediatric IIH.

\section{Pathophysiology}

The association between obesity and IIH is indisputable, although its exact mechanism remains poorly understood. Observational and epidemiological studies have described a possible association of increased intracranial pressure (ICP) with abnormal vitamin A metabolism. Theory related to hypervitaminosis A and IIH is conflicting. It is speculated that raised vitamin A level in cerebrospinal fluid (CSF) reduces brain water absorption by increasing all transretinoic acid gene expression at arachnoid granulation cap cell, ependymal and glial cells. ${ }^{14}$ Although earlier reports revealed raised retinol level in CSF of IIH patients, the recent Idiopathic Intracranial Hypertension Treatment Trial (IIHTT) reported that CSF vitamin A toxicity was an unlikely contributing factor. ${ }^{15-17}$ The research focus of IIH has shifted to consideration of adipose tissue as an actively secreting endocrine organ. ${ }^{18}$ Adipose tissue-derived retinolbinding protein and cytokines like leptin are elevated in obese individuals..$^{19,20}$ It is unclear whether the presence of such metabolites has a role in IIH development, but their identification may provide information about disease pathology.

Intracranial obstructions relating to impaired venous drainage is another pathophysiology of IIH. Observational studies have displayed distal narrowing and stenosis of the transverse cerebral sinus in most IIH cases. ${ }^{21-24}$ Venous sinus stenosis may induce a cycle of venous outflow obstruction, venous hypertension, reduced CSF absorption, and subsequent raised ICP and further compression to the venous system. ${ }^{1}$ It is not known whether this anatomical finding is incidental, causal, or secondary to raised ICP. Transverse venous stenosis is also found in some patients without IIH and may have no functional significance. ${ }^{25}$ Regardless of the cause, endovascular stenting at the site of transverse venous stenosis has shown to reduce venous congestion, improve $\mathrm{CSF}$ absorption, and reduce ICP. ${ }^{26}$ It remains debatable whether the presence of transverse sinus stenosis affects the natural history and prognosis of IIH.

Certain medications (such as oral contraceptive pills, tetracycline, danazol, tamoxifen, lithium, cyclosporin) and a history of polycystic ovary syndrome have been proposed to cause IIH but the evidence is limited owing to small sample sizes. ${ }^{27-29}$ Other factor includes CSF homeostasis involving mutation of the aquaporin- 4 channel that controls brain water movement via transmembrane osmotic shift. ${ }^{30}$ Magnetic resonance spectrometry with metabolic profiling of CSF in IIH has been used to observe pathophysiological mechanisms. ${ }^{31}$ There is still no unifying pathophysiological explanation, and further studies are required.

\section{Clinical features}

Symptoms of raised ICP are commonly present in IIH. Headache is documented in $62 \%$ to $91 \%$ of patients and is characterized by frontal, severe, pulsatile pain that is worse when lying supine or aggravated by Valsalva maneuver during early morning. ${ }^{32-34}$ Often mistaken as migraine, IIH can also be confused with tension headache and analgesic-related headache, except that IIH headache is continuous. In a large prospective cohort study, headache was the most common presentation (89\%). ${ }^{35}$ This can be further complicated when IIH headache is superimposed on headaches of other origin. Reduction of Headache Impact Test -6 score corresponds to disability related to IIH headache. ${ }^{36,37}$ Visual abnormalities are often the sole complaint in IIH. Visual field defect is present in $80 \%$ to $86 \%$ of patients..$^{35,38,39}$ Blind spot enlargement is the most frequent symptom $(80 \%)$, followed by peripheral arcuate defects (72\%) and constrictions (54\%), associated with nerve fiber type damage and depressed perimetric mean deviation visual field sensitivity $(-7.7 \mathrm{~dB}){ }^{39}$ This finding is echoed by the IIHTT. ${ }^{35}$ Visual acuity loss is usually minimal and is unaffected early in the course. Studies have reported diminished visual acuity $(\log M A R \geq 0.2)$ in $17 \%$ of patients and abnormal color vision ( $<5$ out of 6 in Hardy-RandRittler charts) in $14 \% .^{39-41}$ Permanent visual field loss is uncommon. ${ }^{42}$ Transient visual obscurations, characterized by amaurosis lasting for half a minute, occur at a mean of once per month. It is non-specific to IIH and is unrelated to the presenting visual acuity or final visual outcome, although it might represent transient central retinal artery compression..$^{35}$ Other ophthalmic symptoms include reduced color vision (thought to be a result of papilledema) ${ }^{40}$ and pulsatile tinnitus (probably caused by turbulent flow from the venous stenosis over transverse sinus), ${ }^{43}$ which occurs in $60 \%$ of IIH patients on alternate days bilaterally. ${ }^{35}$ Other symptoms include vomiting, retrobulbar pain, photophobia, radicular tenderness over the neck and shoulders, and diplopia. ${ }^{35}$

IIH is often diagnosed incidentally in the absence of symptoms. Papilledema is a hallmark in the diagnosis of IIH. The degree of optic disc swelling is graded according to the Frisen scale where grade 0 is normal disc, grade 1 is very early papilledema, grade 2 is early papilledema, grade 3 is moderate papilledema, grade 4 is marked papilledema, and grade 5 is severe papilledema. ${ }^{44}$ Early papilledema is most frequently seen (33\%). ${ }^{35,39}$ Typically occurring in both eyes, unilateral papilledema and IIH without papilledema have been well described in adults ${ }^{45,46}$ They are often accompanied by optic disc changes such as hyperemia of the optic disc and absent spontaneous venous pulsations. The etiology of unilateral cases is unknown. Optical coherence tomography has been used to measure the peripapillary average retinal thickness to identify subtle disc swelling. ${ }^{47}$ Nonetheless, its role in children has yet to be evaluated, as reference for pediatric parameters is lacking. Relatively low intraocular pressure in the eye has been reported to predispose to retrolaminar hypoperfusion and result in 
disc swelling. ${ }^{40,45}$ Nonetheless, a case series demonstrated no significant intraocular pressure difference between papilledemic eyes. ${ }^{39}$ Papilledema tends to resolve after 3 to 6 months of therapy. ${ }^{48}$ Very infrequently IIH patients go on to develop optic atrophy as a result of long-standing papilledema and disease progression, and thus afferent pupillary defect is uncommon $(5.4 \%) .^{35,39,49}$ Decreased abduction related to raised ICP may be present.$^{50}$ Choroidalretinal folds and macular edema are rare. ${ }^{45}$

In children the symptoms are generally similar. Patterns in adolescents are akin to those in adults. Young children have different presentations. Headache is often intermittent and episodic rather than continuous. ${ }^{51}$ Verbalizing symptoms of headache can be difficult because of non-specificity and misinterpretation as dizziness, neck and shoulder tenderness, or generalized fatigue. Differentiating IIH headache from intracranial neoplasm is by exclusion only. Brain tumor headaches tend to be nocturnal, deep aching, intermittent, and upon rising..$^{52}$ Other suspicion of pyramidal neurological deficits should indicate a diagnosis of central etiology. The pattern of field defect is similar and occurs in $91 \%$ of pediatric patients..$^{32,38,53}$ Nonetheless, expression problems may delay detection of symptoms, and some patients may compensate field loss by head tilt and accommodation. Up to $6 \%$ to $20 \%$ of children present with visual acuity loss..$^{33,38,54}$ Other visual complaints include photophobia and transient vision loss described as 'shimmering lights with colored centers' ${ }^{34}$ The pattern of papilledema is similar to that in adults. Care should be taken to differentiate papilledema from disc swelling secondary to infective causes, ischemic optic neuropathy, demyelination, pseudo-papilledema such as congenital dysplastic disc or Leber hereditary optic neuropathy. Some children with IIH may present without papilledema, ${ }^{46}$ with an estimated prevalence of $5.7 \% .^{55,56}$ In infants $<18$ months of age, a patent fontanelle or open sutures may have contributed to the absence of papilledema. ${ }^{54,57}$ In older pediatric patients, optic nerve sheath abnormalities have been hypothesized. In any case, the absence of papilledema tends to give a better visual outcome. ${ }^{58}$ Proptosis secondary to chronic raised ICP has been described in adults but has not been observed in IIH pediatric cohorts.

\section{Diagnostic challenges}

The modified Dandy criteria is the gold standard for diagnosing IIH. ${ }^{59}$ It comprises 4 key elements: (1) the presence of signs and symptoms of increased ICP (headaches, nausea, vomiting, transient visual obscurations, papilledema), (2) the lack of localizing focal neurological signs except unilateral or bilateral abducens nerve paresis, (3) CSF

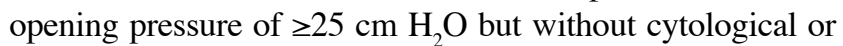
chemical abnormalities, and (4) neuroimaging adequate to exclude cerebral venous thrombosis. When IIH is suspected, clinicians should collect a thorough medical history of the patient, particularly the onset and characteristics of raised ICP symptoms, relevant drug history, followed by detailed documentation of their visual acuity, color vision, fields, ocular motility, pupillary examination, slit lamp and fundal examination, and neurological examination (Figures 1 and 2). Visual field testing should also be performed if permissible. Humphrey 30-2 (Swedish interactive thresholding algorithm) is preferred over 24-2 for improved sensitivity. ${ }^{56}$ This should be followed by imaging of the head to exclude a secondary intracranial cause, and confirmed with diagnostic lumbar puncture for opening pressure. It is also advisable to perform ocular coherence tomography for the optic disc and retinal nerve fiber layer and repeat it at intervals for serial monitoring.

There are limitations to these diagnostic criteria in adults and children. The symptoms should only reflect those of raised ICP or papilledema. Headache, double vision, and pulsatile tinnitus represent typical symptoms of IIH. Less typical symptoms such as neck, shoulder radicular pain or diplopia should be handled with caution. Non-specific symptoms such as nausea, vomiting, and photophobia may exist. Transient visual obscuration and visual field loss may only be exhibited in the presence of papilledema. When early central visual field loss is encountered without signs of chronic papilledema, other causes such as inflammatory optic neuropathy should be considered. When seizure, focal neurological complaints, or encephalopathy are involved, central etiologies should be suspected.

The diagnosis of IIH can be established even if the patient is asymptomatic but exhibiting relevant signs. Atypical signs include third nerve palsy, intranuclear ophthalmoplegia, squint, and meningism. ${ }^{59}$ These should indicate the diagnosis of intracranial neoplasm, subacute meningoencephalitis, central sinus thrombosis, or venous infarction other than IIH. ${ }^{60}$ There are reports describing diagnosis of $\mathrm{IIH}$ without signs of papilledema. Caution should also be taken for possible anatomical variance of optic nerve head vasculature, optic nerve sheath abnormality, and pre-existing glaucomatous optic neuropathy.

Accurate measurement of raised ICP could be challenging in patients with IIH. Diagnosis of IIH requires a lumbar opening pressure of $\geq 25 \mathrm{~cm} \mathrm{H}_{2} \mathrm{O}$ with the patient lying in the lateral decubitus position with legs extended to eliminate Valsalva maneuver. ${ }^{61}$ Typically the mean CSF pressure in $\mathrm{IIH}$ is raised at $35 \mathrm{~cm} \mathrm{H}_{2} \mathrm{O}$ and has no sex or

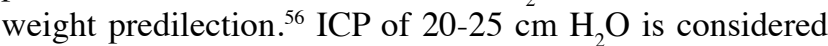
undiagnostic. ${ }^{62}$ Lumbar puncture should be repeated in highly suspicious cases owing to the dynamic nature of ICP. $^{63}$

Adequately excluding secondary causes of intracranial hypertension is important. Computer tomography remains the first line of investigation to exclude hydrocephalus and space-occupying lesions. Magnetic resonance imaging (MRI) with contrast may be superior in the detection of specific IIH changes and to exclude leptomeningeal infiltration and isodense tumors. Emerging evidence has shown that $\mathrm{IIH}$ exhibits specific radiological signs: (1) flattening of the posterior pole of the eyes, (2) dilatation and tortuosity of the 


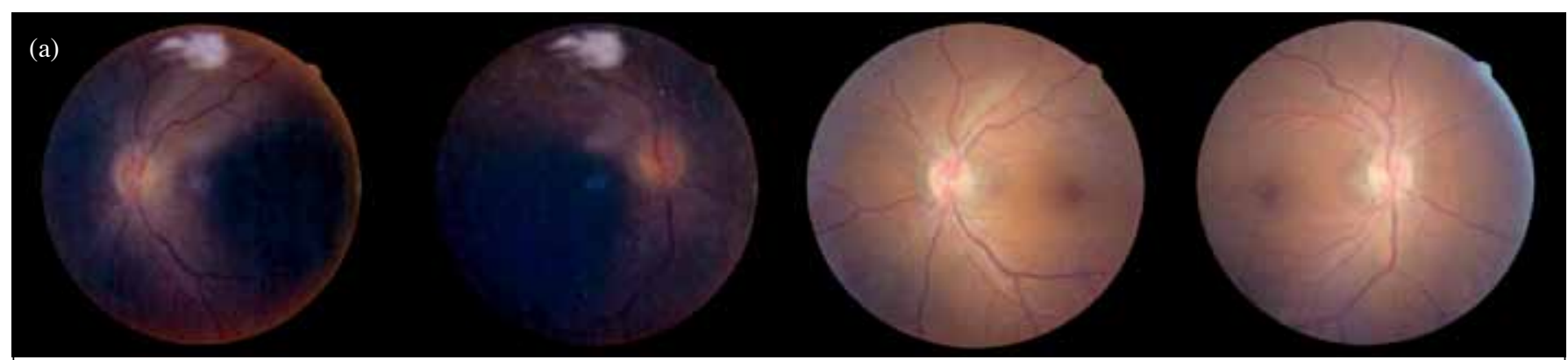

(b)
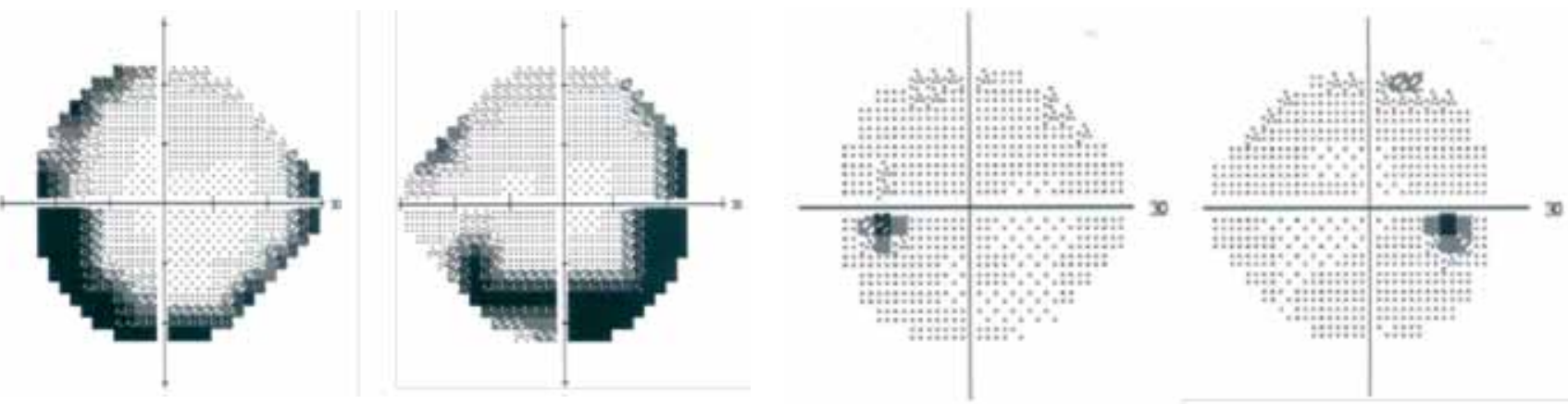

(c)
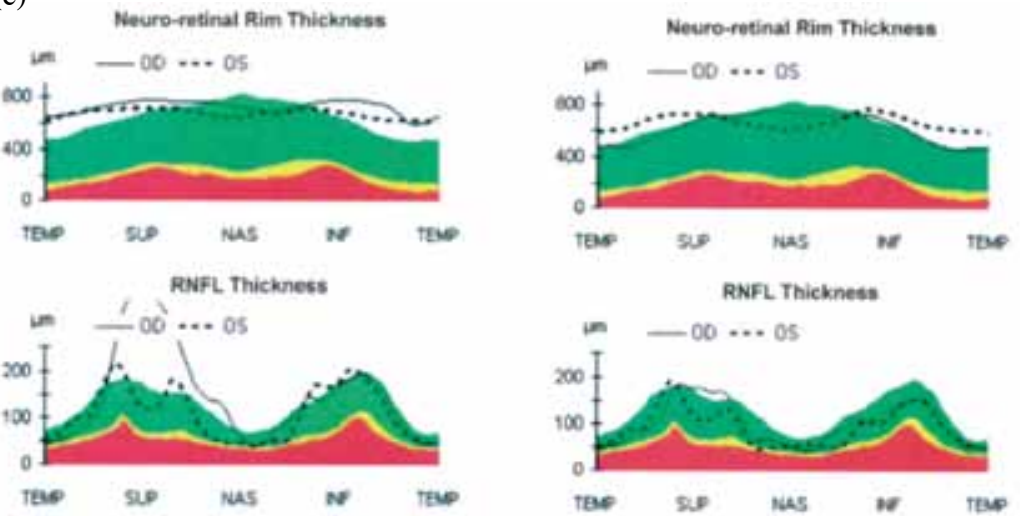
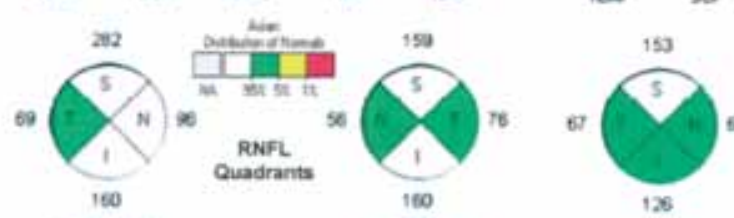

160

$$
204 \times 2 \text { 279 }
$$
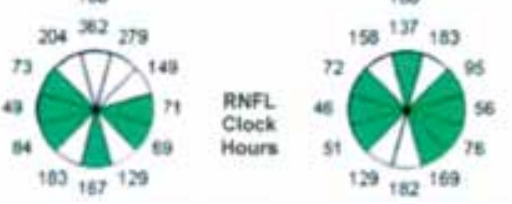
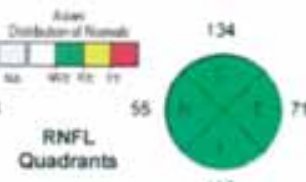

117

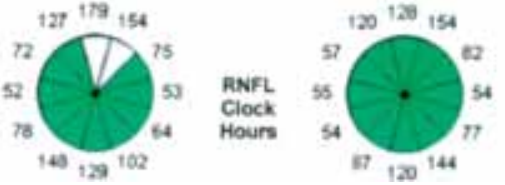

Figure 1.51-year-old woman with chronic hypertension presented with a 1-month history of progressive right-sided blurred vision, headache, and visual obscuration associated with tinnitus without apparent causative factors. She had a sthenic body habitus and was overweight (body mass index, $24.4 \mathrm{~kg}$ / $\mathrm{m}^{2}$ ). A diagnosis of idiopathic intracranial hypertension was made based on the Dandy criteria. She was prescribed acetazolamide $250 \mathrm{mg}$ twice daily and was advised to loss weight. Three months later, her body mass index has reduced to $23.4 \mathrm{~kg} / \mathrm{m}^{2}$. Ophthalmic examination showed improvement of bestcorrected visual acuity from 0.6 to 0.7 in the right eye and from 0.7 to 0.8 in the left eye. (a) Fundal examination revealed improvement from bilateral disc swelling to normal disc margins with residual pigmentations. (b) Visual field examination showed improvement from bilateral arcuate constriction to near total resolution of visual field defects. (c) Optical coherence tomography showed resolution of optic disc retinal nerve fiber layer thickness. Before treatment, magnetic resonance imaging of the brain and orbit showed no space-occupying lesion or abnormal contrast enhancement. (d) Magnetic agnetic resonance venogram of the brain showed no evidence of venous sinus stenosis or thrombosis. Her transverse sinus was narrower on the left side (although asymmetry is common). Opening pressure from lumbar puncture was $27 \mathrm{~cm} \mathrm{H}_{2} \mathrm{O}$ with normal composition and negative culture. 


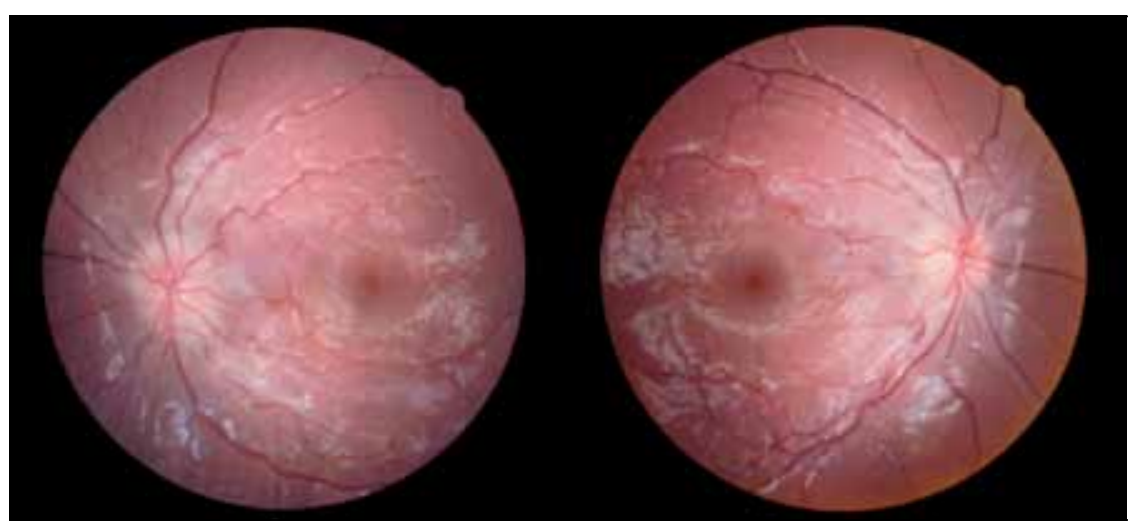

Figure 2. Russel Silver syndrome mimicking idiopathic intracranial hypertension in a 5 -year-old boy who had an incidental finding of bilateral disc swelling. He was developmentally delayed, short-statured and failed to thrive. Brain imaging and lumbar puncture opening pressure were normal. He was asymptomatic and had normal visual field. He was suspected to have Russel Silver syndrome (a genetic condition affecting chromosomes 7 and 11), which is characterized by short stature, triangular face, clinodactyly, hemi-hypertrophy, hypoglycemia, and failure to thrive.

optic nerve sheaths, (3) empty sella turcica, and (4) stenosis of one or both transverse cerebral venous sinuses. ${ }^{1,64}$ When interpreting images, it is important to differentiate central venous sinus thromboses from transverse venous stenosis, which is more specific to IIH. There is no consensus on routine screening with MRI. When uncertain, MRI venogram should also be used. In pediatric patients, MRI is the choice for diagnosing IIH, although issues with sedation, contrast allergy, renal impairment, and presence of an implanted medical device may preclude its use. In addition, secondary causes of raised ICP should be ruled out, such as Addison's disease, obstructive sleep apnea, pulmonary hypertension, and medications such as contraceptives. MRI should also be used in 'atypical' patients: males, non-obese, elderly, or prepubertal children. ${ }^{65-67}$

Diagnosis in children is also based on the modified Dandy criteria, but application of adult-derived criteria to all age groups is disputable. Children present a different spectrum of diagnostic challenge owing to non-specific complaints and variability in symptoms, and they may articulate insufficiently. This may explain why children have more visual damage because of delayed diagnosis. Pediatric patients may exhibit atypical signs such as cerebellar and long-track signs that mimic a posterior fossa spaceoccupying lesion. This may be further complicated by behavioral changes such as head banging and generalized non-specific irritability or solemnness. ${ }^{46}$

The norm and cut-off opening ICP that satisfies the diagnosis of IIH in children are difficult to determine. ICP varies with age: $8.2 \mathrm{~cm} \mathrm{H} 2 \mathrm{O}$ represents a normal opening pressure in infants, slowly increasing to $18 \mathrm{~cm} \mathrm{H}_{2} \mathrm{O}$ in children aged 8 years, eventually reaching an upper limit of $20 \mathrm{~cm} \mathrm{H}_{2} \mathrm{O}$ in children $>8$ years old ${ }^{68,69}$ In 2010, a diagnostic ICP for IIH was proposed: an opening pressure of $>20 \mathrm{~cm} \mathrm{H}_{2} \mathrm{O}$ in children $<8$ years old and $>25 \mathrm{~cm} \mathrm{H}_{2} \mathrm{O}$ in those $>8$ years old. ${ }^{55}$ Nonetheless, a false high opening pressure may be observed in crying children or anxious patients. Lumbar puncture under light sedation is recommended. Fluctuations in ICP should be taken into account and a child may not meet the diagnostic ICP. ${ }^{63,70,71}$ In cases of a high suspicion of IIH, a second opening pressure may be necessary. In rare circumstances a lumbar drain with a transducer has been used for monitoring. ${ }^{72}$
The onset of symptoms should also be considered. Patients with rapid onset or fulminant progressive deterioration should raise a concern for cerebral vasculopathy. Nevertheless, conditions that masquerade as IIH should be ruled out. Conditions previously thought to be associated with IIH such as medications (oral contraceptive pills, retinoids), lupus, and vasculitis are now believed to be related to venous sinus thrombosis rather than IIH as a result of hypercoagulability. ${ }^{73,74}$ If in doubt, ocular retinal nerve fiber layer scanning may pick up subtle changes in the optic disc. ${ }^{47,75}$ Serial fundus photographs and fluorescent angiogram can also be used.

\section{Treatment}

The goals of managing IIH are vision preservation and alleviation of symptoms. Weight loss remains crucial as the first-line and long-term management and its effects linger. The trend of weight control is an indicator for recurrence of disease. A weight loss of $5 \%$ to $10 \%$ results in control of symptomology, signs, and ICP. ${ }^{76}$ Other weight-control methods such as dietetic strategies (low salt, low calorie diet), exercise regimens, and bariatric surgery could be considered. ${ }^{1,77}$ Treatment of endocrine and metabolic morbidities such as obesity and diabetes may have dual effects of weight reduction and theoretic alteration of homeostasis of ICP. Lumbar puncture is indicated for diagnosis and treatment, and is usually the first attempt for symptom relief. ${ }^{78}$ This mode of therapy can have a lasting effect for a few months to years, with some patients requiring only one treatment. Patients with persistent symptoms and signs usually undergo serial lumbar punctures.

In patients whose visual function is impaired, medication such as acetazolamide can be prescribed in parallel. Acetazolamide, a carbonic anhydrase inhibitor, can reduce cerebral fluid production. Combination therapy with a carbonic anhydrase inhibitor and weight loss is efficacious. The multicenter, double-blind, randomized controlled IIHTT showed that the use of acetazolamide with a low-sodium weight-reduction diet resulted in modest improvement in visual field function and papilledema grade at 6 months compared with diet alone. Nonetheless, the long-term effects and functional correlation of visual field improvement are unknown. The recommended dose 
of acetazolamide for adults is 1-2 g/day in divided doses, titrated to a maximum dose of $4 \mathrm{~g} /$ day. ${ }^{79}$ In pre-pubertal children, the dose is started at $15-25 \mathrm{mg} / \mathrm{kg} / \mathrm{day}$ and titrated to a maximum dose of $100 \mathrm{mg} / \mathrm{kg} / \mathrm{day} .^{58,80-82}$ Postpubertal children are generally treated with an adult dose. ${ }^{83}$ Dose of acetazolamide can be up-titrated as long as it is required and clinically tolerated. Nonetheless, sole use of acetazolamide achieves varying success, and its efficacy in children remains unknown. Moreover, the side-effects of acetazolamide include hypokalemia, metabolic acidosis, development of renal calculi, transaminitis, pancreatitis, and failure to thrive in long-term use. ${ }^{48}$ Mineralocorticoid, in the form of methylprednisolone at $15 \mathrm{mg} / \mathrm{kg}$, is another treatment option for acute vision loss ${ }^{84}$ Intravenous injection at a high dose can be used for severe vision loss and to delay surgical treatment. ${ }^{85}$ In children, methylprednisolone can be prescribed at $2 \mathrm{mg} / \mathrm{kg} /$ day for 2 weeks and tapered over 2 weeks. Other oral medications such as topiramate, zonisamide, octreotide, mannitol, and frusemide can be used when other medications are contraindicated. ${ }^{86-88}$ There is no consensus on treatment duration. It has been suggested that medications be continued until visual function and symptoms have stabilized for at least 6 months. ${ }^{89}$ Headache usually resolves in response to lowered ICP. Long-term headache can be treated with breakthrough analgesic such as acetaminophen, non-steroidal anti-inflammatory agents or prophylactic agents such as propranolol, amitriptyline, topiramate, and valproate. It is important to be alert for analgesic headache and rebound headache. Non-steroidal anti-inflammatory agents should be avoided in children for fear of Reye's syndrome..$^{90}$ Resistant cases invariably require surgical treatment.

Surgical intervention (optic nerve sheath fenestration [ONSF] and CSF shunting) is recommended in fulminant and intractable cases where vision loss is imminent. ${ }^{85}$ ONSF is the treatment of choice in cases with acute deterioration in visual function alone..$^{91,92}$ ONSF can be performed medially or laterally through incision of the arachnoid dura via a transconjunctival orbitotomy approach. ONSF may stabilize visual acuity, visual field, reduce papilledema and headaches. ${ }^{91-93}$ Bilateral stabilization of visual function after unilateral ONSF has also been reported. ${ }^{94,95}$ Adverse effects of ONSF include permanent vision loss, pupillary dysfunction, and recurrence. Up to $12 \%$ to $33 \%$ of cases demonstrate vision improvement initially but deterioration later. ${ }^{96,97}$

In patients with intractable headache and acute progressive vision loss, CSF drainage using a ventriculo-peritoneal shunt or lumbo-peritoneal shunt is preferred. CSF shunting can halt progression of vision loss and is the most widely performed surgery for IIH. ${ }^{98-100}$ Current evidence does not suggest superiority of one procedure over another. Nonetheless, ventriculo-peritoneal shunts have a higher failure rate, whereas lumbo-peritoneal shunts need more revision. ${ }^{101}$ In addition, CSF shunting is associated with risks of infection, intracranial bleeding, and acquired Chiari malformation..$^{98}$ The long-term outcome of visual function has yet to be determined.
Endovascular stenting also improves symptoms and preserves vision in selected cases of transverse venous stenosis by reducing venous pressure and $\mathrm{ICP}^{26,102}$ Placement of the stent over the distal transverse sinus or transverse-sigmoid sinus junction is followed by dual antiplatelet therapy for 6 months, and then aspirin for 1-2 years. Nonetheless, it is associated with serious complications such as in-stent migration, restenosis, subdural hemorrhage, and infection..$^{26,102}$ Given its risk and morbidity, endovascular stenting should be offered only to cases of profound vision loss, fulminant symptoms where medical treatment has been exhausted and when ONSF and CSF shunting are contraindicated.

Management in pediatric cases is mostly medical. Most pediatric patients respond to initial lumbar puncture at diagnosis. ${ }^{89}$ Serial lumbar punctures are often unwelcomed owing to the associated pain and need for admission, sedation, and monitoring. ${ }^{103}$ The current first-line treatment with carbonic anhydrase inhibitor is acetazolamide. The problems with long-term carbonic anhydrase inhibitors are electrolyte imbalance, failure to thrive, and renal calcification. All can be further complicated by noncompliance. The treatment duration should be the same as for adults. Substitution with frusemide or topiramate may be needed when acetazolamide is ineffective or contraindicated. Weight control remains the long-term goal as for adult IIH patients. ${ }^{104}$ Rarely surgical options are applied in children with severe headache and fulminant visual function deterioration. ONSF and CSF shunting have shown varying success. Problems related to children specifically in lumboperitoneal shunting are shunt migration, mechanical fracture, and obstruction due to longitudinal growth of the spine..$^{98,105}$ Experience in stenting of a transverse venous stenosis in pediatric patients is lacking. Surgical procedures for pediatric IIH should be limited to selective patients.

\section{Prognosis}

Permanent and severe vision loss has been reported in $6 \%$ to $9 \%$ of adults and $10 \%$ of children with $\mathrm{IIH} . .^{12,33,53,106,107}$ The incidence of blindness secondary to IIH is approximately $1 \%$ to $2 \% .^{108}$ The degree of obesity is proportional to the amount of vision loss. ${ }^{109}$ Other visual complaints such as transient visual obscurations, papilledema, duration of symptoms, and presence of cranial nerve palsies are not associated with worse visual outcomes. ${ }^{43,50,110}$ In a few patients, symptoms of headache persist even after management of raised ICP. ${ }^{111}$

The rate of recurrence of $\mathrm{IIH}$ is $8 \%$ to $10 \%$ in adults and $6 \%$ to $22 \%$ in children. ${ }^{12,33,53,71,112,113}$ Recurrence typically occurs within 2 to 5 years of diagnosis, with no sex predilection. Multiparous women seemed to have more recurrence. ${ }^{39}$ Changes in visual acuity and field are usually the chief complaint in recurrence and typically occur in those who lose weight initially and regain thereafter. ${ }^{109,114}$ Weight control is predictive of recurrence. ${ }^{109} \mathrm{~A}$ weight gain of $6 \%$ is associated with recurrence. ${ }^{114}$ Obesity in pre-pubertal children increases the rate of recurrence five-fold. ${ }^{115}$ Strict weight management is therefore imperative to minimize 
fluctuations. Frequent monitoring of visual function, body mass index, and compliance is indicated.

\section{Conclusion}

IIH is an uncommon neuro-ophthalmological entity that may result in permanent visual disability. Recognition of clinical symptoms and the use of imaging modalities are essential in diagnosing IIH and excluding secondary causes. Pediatric cases are rare and diagnosis remains difficult owing to variability of symptoms and non-specificity. Diagnosis in atypical patients such as males and non-obese patients should be made with caution. Treatment options include weight loss, lumbar puncture, and acetazolamide. Surgery is reserved for refractory cases. Most visual acuity and field loss are mild and reversible but depend on weight control, recurrence, and timing of diagnosis. The trend of IIH is expected to increase due to the global endemic of obesity. The management of pediatric and adult cases are different and should be individualized.

\section{Declaration}

The authors have no conflicts of interest to disclose.

\section{References}

1. Biousse V, Bruce BB, Newman NJ. Update on the pathophysiology and management of idiopathic intracranial hypertension. J Neurol Neurosurg Psychiatry. 2012;83:48894.

2. Raoof N, Sharrack B, Pepper IM, Hickman SJ. The incidence and prevalence of idiopathic intracranial hypertension in Sheffield, UK. Eur J Neurol. 2011;18:1266-8.

3. Yabe I, Moriwaka F, Notoya A, Ohtaki M, Tashiro K. Incidence of idiopathic intracranial hypertension in Hokkaido, the northernmost island of Japan. J Neurol. 2000;247:474-5.

4. Liu IH, Wang AG, Yen MY. Idiopathic intracranial hypertension: clinical features in Chinese patients. Jpn J Ophthalmol.2011;55:138-42.

5. Daniels AB, Liu GT, Volpe NJ, et al. Profiles of obesity, weight gain, and quality of life in idiopathic intracranial hypertension (pseudotumor cerebri). Am J Ophthalmol. 2007;143:635-41.

6. Bruce BB, Kedar S, Van Stavern GP, et al. Idiopathic intracranial hypertension in men. Neurology. 2009;72:304-9.

7. Mrejen S, Vignal C, Bruce BB, et al. Idiopathic intracranial hypertension: a comparison between French and NorthAmerican white patients. Rev Neurol (Paris). 2009;165:542-8.

8. Kim TW, Choung HK, Khwarg SI, Hwang JM, Yang HJ. Obesity may not be a risk factor for idiopathic intracranial hypertension in Asians. Eur J Neurol. 2008;15:876-9.

9. Ko MW, Liu GT. Pediatric idiopathic intracranial hypertension (pseudotumor cerebri). Horm Res Paediatr. 2010;74:381-9.

10. Lau WL, Ko CH, Cheng WW, Yau SK, Lee CY. Idiopathic intracranial hypertension in children: case report and estimation of local incidence. Hong Kong J Paediatr (new series). 2014;19:28-31.

11. Gordon K. Pediatric pseudotumor cerebri: descriptive epidemiology. Can J Neurol Sci. 1997;24:219-21.

12. Cinciripini GS, Donahue S, Borchert MS. Idiopathic intracranial hypertension in prepubertal pediatric patients: characteristics, treatment, and outcome. Am J Ophthalmol. 1999;127:178-82.

13. Sheldon CA, Paley GL, Xiao R, et al. Pediatric idiopathic intracranial hypertension: age, gender, and anthropometric features at diagnosis in a large, retrospective, multisite cohort. Ophthalmology. 2016;123:2424-31.

14. Kristensen B, Malm J, Markgren P, Ekstedt J. CSF hydrodynamics in superior sagittal sinus thrombosis. J Neurol Neurosurg Psychiatry. 1992;55:287-93.

15. Warner JE, Larson AJ, Bhosale P, et al. Retinol-binding protein and retinol analysis in cerebrospinal fluid and serum of patients with and without idiopathic intracranial hypertension. J Neuroophthalmol.2007;27:258-62.
16. Tabassi A, Salmasi AH, Jalali M. Serum and CSF vitamin A concentrations in idiopathic intracranial hypertension. Neurology. 2005;64:1893-6.

17. Libien J, Kupersmith MJ, Blaner W, et al. Role of vitamin A metabolism in IIH: results from the idiopathic intracranial hypertension treatment trial. J Neurol Sci. 2017;372:78-84.

18. Wozniak SE, Gee LL, Wachtel MS, Frezza EE. Adipose tissue: the new endocrine organ? A review article. Dig Dis Sci. 2009;54:1847-56.

19. Ooi LY, Walker BR, Bodkin PA, Whittle IR. Idiopathic intracranial hypertension: can studies of obesity provide the key to understanding pathogenesis? Br J Neurosurg. 2008;22:187-94.

20. Libien J, Blaner WS. Retinol and retinol-binding protein in cerebrospinal fluid: can vitamin A take the "idiopathic" out of idiopathic intracranial hypertension? J Neuroophthalmol. 2007;27:253-7.

21. Rohr A, Bindeballe J, Riedel C, et al. The entire dural sinus tree is compressed in patients with idiopathic intracranial hypertension: a longitudinal, volumetric magnetic resonance imaging study. Neuroradiology. 2012;54:25-33.

22. Sander K, Poppert H, Etgen T, Hemmer B, Sander D. Dynamics of intracranial venous flow patterns in patients with idiopathic intracranial hypertension. Eur Neurol. 2011;66:334-8.

23. Bateman GA, Stevens SA, Stimpson J. A mathematical model of idiopathic intracranial hypertension incorporating increased arterial inflow and variable venous outflow collapsibility. J Neurosurg. 2009;110:446-56.

24. Strydom MA, Briers N, Bosman MC, Steyn S. The anatomical basis of venographic filling defects of the transverse sinus. Clin Anat. 2010;23:153-9.

25. Farb RI, Vanek I, Scott JN, et al. Idiopathic intracranial hypertension: the prevalence and morphology of sinovenous stenosis. Neurology. 2003;60:1418-24.

26. Albuquerque FC, Dashti SR, Hu YC, et al. Intracranial venous sinus stenting for benign intracranial hypertension: clinical indications, technique, and preliminary results. World Neurosurg. 2011;75:648-55.

27. Chiu AM, Chuenkongkaew WL, Cornblath WT, et al. Minocycline treatment and pseudotumor cerebri syndrome. Am J Ophthalmol. 1998;126:116-21.

28. Kesler A, Goldhammer Y, Hadayer A, Pianka P. The outcome of pseudotumor cerebri induced by tetracycline therapy. Acta Neurol Scand. 2004;110:408-11.

29. Friedman DI. Medication-induced intracranial hypertension in dermatology. Am J Clin Dermatol. 2005;6:29-37.

30. Ekizoglu E, Icoz S, Tuzun E, et al. Aquaporin-4 antibodies are not present in patients with idiopathic intracranial 
hypertension. Cephalalgia. 2012;32:198-202.

31. Sinclair AJ, Viant MR, Ball AK, et al. NMR-based metabolomic analysis of cerebrospinal fluid and serum in neurological diseases--a diagnostic tool? NMR Biomed. 2010;23:123-32.

32. Babikian P, Corbett J, Bell W. Idiopathic intracranial hypertension in children: the Iowa experience. J Child Neurol. 1994;9:144-9.

33. Phillips PH, Repka MX, Lambert SR. Pseudotumor cerebri in children. J AAPOS. 1998;2:33-8.

34. Soler D, Cox T, Bullock P, Calver DM, Robinson RO. Diagnosis and management of benign intracranial hypertension. Arch Dis Child. 1998;78:89-94.

35. Wall M, Kupersmith MJ, Kieburtz KD, et al. The idiopathic intracranial hypertension treatment trial: clinical profile at baseline. JAMA Neurol. 2014;71:693-701.

36. Bjorner JB, Kosinski M, Ware JE Jr. Using item response theory to calibrate the Headache Impact Test (HIT) to the metric of traditional headache scales. Qual Life Res. 2003;12:981-1002.

37. Kosinski M, Bayliss MS, Bjorner JB, et al. A six-item shortform survey for measuring headache impact: the HIT-6. Qual Life Res. 2003;12:963-74.

38. Salman MS, Kirkham FJ, MacGregor DL. Idiopathic "benign" intracranial hypertension: case series and review. J Child Neurol. 2001;16:465-70.

39. Pollak L, Zohar E, Glovinsky Y, Huna-Baron R. Reevaluation of presentation and course of idiopathic intracranial hypertension--a large cohort comprehensive study. Acta Neurol Scand. 2013;127:406-12.

40. Fraser C, Plant GT. The syndrome of pseudotumour cerebri and idiopathic intracranial hypertension. Curr Opin Neurol. 2011;24:12-7.

41. Randhawa S, Van Stavern GP. Idiopathic intracranial hypertension (pseudotumor cerebri). Curr Opin Ophthalmol. 2008;19:445-53.

42. Bidot $S$, Bruce BB, Saindane AM, Newman NJ, Biousse $V$. Asymmetric papilledema in idiopathic intracranial hypertension. J Neuroophthalmol. 2015;35:31-6.

43. Wall M, George D. Idiopathic intracranial hypertension. A prospective study of 50 patients. Brain. 1991;114:155-80.

44. Frisén L. Swelling of the optic nerve head: a staging scheme.J Neurol Neurosurg Psychiatry. 1982;45:13-8.

45. Yau GS, Lee JW, Chan TT, Yuen CY. Unilateral papilledema and choroidal folds: an uncommon presentation of idiopathic intracranial hypertension. Surgery Curr Res. 2014;4:193.

46. Beri S, Gosalakkal JA, Hussain N, Balky AP, Parepalli S. Idiopathic intracranial hypertension without papilledema. Pediatr Neurol. 2010;42:56-8.

47. Skau M, Milea D, Sander B, Wegener M, Jensen R. OCT for optic disc evaluation in idiopathic intracranial hypertension. Graefes Arch Clin Exp Ophthalmol. 2011;249:723-30.

48. NORDIC Idiopathic Intracranial Hypertension Study Group Writing Committee, Wall M, McDermott MP, et al. Effect of acetazolamide on visual function in patients with idiopathic intracranial hypertension and mild visual loss: the idiopathic intracranial hypertension treatment trial. JAMA. 2014;311:1641-51.

49. Radhakrishnan K, Thacker AK, Bohlaga NH, Maloo $J C$, Gerryo SE. Epidemiology of idiopathic intracranial hypertension: a prospective and case-control study. J Neurol Sci. 1993;116:18-28.

50. Rush JA. Pseudotumor cerebri: clinical profile and visual outcome in 63 patients. Mayo Clin Proc. 1980;55:541-6.

51. Hershey AD, Powers SW, Winner P, Kabbouche MA. Pediatric Headaches in Clinical Practice. John Wiley \& Sons; 2009.

52. Suwanwela N, Phanthumchinda K, Kaoropthum S.
Headache in brain tumor: a cross-sectional study. Headache. 1994;34:435-8.

53. Kesler A, Fattal-Valevski A. Idiopathic intracranial hypertension in the pediatric population. J Child Neurol. 2002;17:745-8.

54. Youroukos S, Psychou F, Fryssiras S, Paikos P, Nicolaidou $P$. Idiopathic intracranial hypertension in children. J Child Neurol. 2000;15:453-7.

55. Standridge SM. Idiopathic intracranial hypertension in children: a review and algorithm. Pediatr Neurol. 2010;43:377-90.

56. Digre KB, Nakamoto BK, Warner JE, Langeberg WJ, Baggaley SK, Katz BJ. A comparison of idiopathic intracranial hypertension with and without papilledema. Headache. 2009:49:185-93.

57. Suzuki H, Takanashi J, Kobayashi K, Nagasawa K, Tashima K, Kohno Y. MR imaging of idiopathic intracranial hypertension. AJNR Am J Neuroradiol. 2001;22:196-9.

58. Rangwala LM, Liu GT. Pediatric idiopathic intracranial hypertension. Surv Ophthalmol. 2007;52:597-617.

59. Friedman DI, Jacobson DM. Diagnostic criteria for idiopathic intracranial hypertension. Neurology. 2002;59:1492-5.

60. Friedman DI, Forman S, Levi L, Lavin PJ, Donahue $S$. Unusual ocular motility disturbances with increased intracranial pressure. Neurology. 1998;50:1893-6.

61. Corbett JJ, Mehta MP. Cerebrospinal fluid pressure in normal obese subjects and patients with pseudotumor cerebri. Neurology. 1983;33:1386-8.

62. Digre KB, Corbett JJ. Idiopathic intracranial hypertension (pseudotumor cerebri): a reappraisal. Neurologist. 2001;7:267.

63. Sklar FH, Beyer CW Jr, Ramanathan M, Cooper PR, Clark WK. Cerebrospinal fluid dynamics in patients with pseudotumor cerebri. Neurosurgery. 1979;5:208-16.

64. Agid R, Farb RI, Willinsky RA, Mikulis DJ, Tomlinson G. Idiopathic intracranial hypertension: the validity of crosssectional neuroimaging signs. Neuroradiology. 2006;48:5217.

65. Lee AG, Brazis PW. Magnetic resonance venography in idiopathic pseudotumor cerebri. J Neuroophthalmol. 2000;20:12-3.

66. Sylaja PN, Ahsan Moosa NV, Radhakrishnan K, Sankara Sarma P, Pradeep Kumar S. Differential diagnosis of patients with intracranial sinus venous thrombosis related isolated intracranial hypertension from those with idiopathic intracranial hypertension. J Neurol Sci. 2003;215:9-12.

67. Leker RR, Steiner I. Features of dural sinus thrombosis simulating pseudotumor cerebri. Eur J Neurol. 1999;6:601-4.

68. Kotagal S. Increased Intracanial Pressure. In: Swaiman KF, Ashwal S, Ferriero DM, editors. Pediatric Neurology: Principles and Practice. Mosby Elsevier; 1999.

69. Welch $K$. The intracranial pressure in infants. J Neurosurg. 1980;52:693-9.

70. Lyons MK, Meyer FB. Cerebrospinal fluid physiology and the management of increased intracranial pressure. Mayo Clin Proc. 1990;65:684-707.

71. Johnston L, Paterson A. Benign intracranial hypertension. I. Diagnosis and prognosis. Brain. 1974;97:289-300.

72. Skau M, Brennum J, Gjerris F, Jensen R. What is new about idiopathic intracranial hypertension? An updated review of mechanism and treatment. Cephalalgia. 2006;26:384-99.

73. Wechsler B, Vidailhet M, Piette JC, et al. Cerebral venous thrombosis in Behcet's disease: clinical study and long-term follow-up of 25 cases. Neurology. 1992;42:614-8.

74. Vachvanichsanong P, Dissaneewate P. Childhood systemic lupus erythematosus in Songklanagarind Hospital: a potential 
unique subgroup. Clin Rheumatol. 1993;12:346-9.

75. Padhye LV, Van Stavern GP, Sharma A, Viets R, Huecker JB, Gordon MO. Association between visual parameters and neuroimaging features of idiopathic intracranial hypertension. J Neurol Sci. 2013;332:80-5.

76. Wong R, Madill SA, Pandey P, Riordan-Eva P. Idiopathic intracranial hypertension: the association between weight loss and the requirement for systemic treatment. BMC Ophthalmol. 2007;7:15.

77. Fridley J, Foroozan R, Sherman V, Brandt ML, Yoshor D. Bariatric surgery for the treatment of idiopathic intracranial hypertension. J Neurosurg. 2011;114:34-9.

78. De Simone R, Marano E, Fiorillo C, et al. Sudden re-opening of collapsed transverse sinuses and longstanding clinical remission after a single lumbar puncture in a case of idiopathic intracranial hypertension. Pathogenetic implications. Neurol Sci. 2005;25:342-4.

79. Gücer $G$, Viernstein L. Long-term intracranial pressure recording in the management of pseudotumor cerebri.J Neurosurg. 1978;49:256-63.

80. Baker RS, Baumann RJ, Buncic JR. Idiopathic intracranial hypertension (pseudotumor cerebri) in pediatric patients. Pediatr Neurol. 1989;5:5-11.

81. Schoeman JF. Childhood pseudotumor cerebri: clinical and intracranial pressure response to acetazolamide and furosemide treatment in a case series. J Child Neurol. 1994;9:130-4.

82. Distelmaier F, Sengler U, Messing-Juenger M, Assmann $B$, Mayatepek E, Rosenbaum T. Pseudotumor cerebri as an important differential diagnosis of papilledema in children. Brain Dev. 2006;28:190-5.

83. Friedman DI. The pseudotumor cerebri syndrome. Neurol Clin. 2014;32:363-96.

84. Liu GT, Glaser JS, Schatz NJ. High-dose methylprednisolone and acetazolamide for visual loss in pseudotumor cerebri. Am J Ophthalmol. 1994;118:88-96.

85. Thambisetty M, Lavin PJ, Newman NJ, Biousse V. Fulminant idiopathic intracranial hypertension. Neurology. 2007;68:22932.

86. Thenuwara K, Todd MM, Brian JE Jr. Effect of mannitol and furosemide on plasma osmolality and brain water. Anesthesiology. 2002;96:416-21.

87. Panagopoulos GN, Deftereos SN, Tagaris GA, et al. Octreotide: a therapeutic option for idiopathic intracranial hypertension. Neurol Neurophysiol Neurosci. 2007;1.

88. Çelebisoy N, Gökçay F, Şirin H, Akyürekli Ö. Treatment of idiopathic intracranial hypertension: topiramate vs acetazolamide, an open-label study. Acta Neurol Scand. 2007;116:322-7.

89. Friedman DI, Jacobson DM. Idiopathic intracranial hypertension. J Neuroophthalmol. 2004;24:138-45.

90. Casteels-Van Daele M, Van Geet C, Wouters C, Eggermont E. Reye syndrome revisited: a descriptive term covering a group of heterogeneous disorders. Eur J Pediatr. 2000;159:641-8.

91. Acheson JF, Green WT, Sanders MD. Optic nerve sheath decompression for the treatment of visual failure in chronic raised intracranial pressure. J Neurol Neurosurg Psychiatry. 1994:57:1426-9.

92. Goh KY, Schatz NJ, Glaser JS. Optic nerve sheath fenestration for pseudotumor cerebri.J Neuroophthalmol. 1997;17:86-91.

93. Mauriello JA Jr, Shaderowfsky P, Gizzi M, Frohman L. Management of visual loss after optic nerve sheath decompression in patients with pseudotumor cerebri. Ophthalmology. 1995;102:441-5.

94. Kelman SE, Heaps $R$, Wolf A, Elman MJ. Optic nerve decompression surgery improves visual function in patients with pseudotumor cerebri. Neurosurgery. 1992;30:391-5.

95. Lee AG, Patrinely JR, Edmond JC. Optic nerve sheath decompression in pediatric pseudotumor cerebri. Ophthalmic Surg Lasers. 1998;29:514-7.

96. Spoor TC, McHenry JG, Shin DH. Long-term results using adjunctive mitomycin $C$ in optic nerve sheath decompression for pseudotumor cerebri. Ophthalmology. 1995;102:2024-8.

97. Spoor TC, McHenry JG. Long-term effectiveness of optic nerve sheath decompression for pseudotumor cerebri. Arch Ophthalmol. 1993;111:632-5.

98. Eggenberger ER, Miller NR, Vitale S. Lumboperitoneal shunt for the treatment of pseudotumor cerebri. Neurology. 1996;46:1524-30.

99. Bynke $G$, Zemack $G$, Bynke H, Romner B. Ventriculoperitoneal shunting for idiopathic intracranial hypertension. Neurology. 2004;63:1314-6.

100. Burgett RA, Purvin VA, Kawasaki A. Lumboperitoneal shunting for pseudotumor cerebri. Neurology. 1997;49:734-9.

101. Abubaker K, Ali Z, Raza K, Bolger C, Rawluk D, O'Brien D. Idiopathic intracranial hypertension: lumboperitoneal shunts versus ventriculoperitoneal shunts--case series and literature review. Br J Neurosurg. 2011;25:94-9.

102. Ahmed RM, Wilkinson M, Parker GD, et al. Transverse sinus stenting for idiopathic intracranial hypertension: a review of 52 patients and of model predictions. AJNR Am J Neuroradiol. 2011:32:1408-14.

103. Thurtell MJ, Wall M. Idiopathic intracranial hypertension (pseudotumor cerebri): recognition, treatment, and ongoing management. Curr Treat Options Neurol. 2013;15:1-12.

104. Wall M, George D. Visual loss in pseudotumor cerebri. Incidence and defects related to visual field strategy. Arch Neurol. 1987;44:170-5.

105. Chumas PD, Kulkarni AV, Drake JM, Hoffman HJ, Humphreys $R P$, Rutka JT. Lumboperitoneal shunting: a retrospective study in the pediatric population. Neurosurgery. 1993;32:376-83.

106. Baheti NN, Nair M, Thomas SV. Long-term visual outcome in idiopathic intracranial hypertension. Ann Indian Acad Neurol. 2011;14:19-22.

107. Radhakrishnan K, Ahlskog JE, Cross SA, Kurland LT, O'Fallon WM. Idiopathic intracranial hypertension (pseudotumor cerebri). Descriptive epidemiology in Rochester, Minn, 1976 to 1990. Arch Neurol. 1993;50:78-80.

108. Best J, Silvestri G, Burton B, Foot B, Acheson J. The incidence of blindness due to idiopathic intracranial hypertension in the UK. Open Ophthalmol J.2013;7:26-9.

109. Ko MW, Chang SC, Ridha MA, et al. Weight gain and recurrence in idiopathic intracranial hypertension: a casecontrol study. Neurology. 2011;76:1564-7.

110. Corbett JJ, Savino PJ, Thompson HS, et al. Visual loss in pseudotumor cerebri. Follow-up of 57 patients from five to 41 years and a profile of 14 patients with permanent severe visual loss. Arch Neurol. 1982;39:461-74.

111. Friedman DI, Rausch EA. Headache diagnoses in patients with treated idiopathic intracranial hypertension. Neurology. 2002;58:1551-3.

112. Weisberg LA. Benign intracranial hypertension. Medicine (Baltimore). 1975;54:197-207.

113. Kesler A, Hadayer A, Goldhammer Y, Almog Y, Korczyn AD. Idiopathic intracranial hypertension: risk of recurrences. Neurology. 2004;63:1737-9.

114. Szewka AJ, Bruce BB, Newman NJ, Biousse V. Idiopathic intracranial hypertension: relation between obesity and visual outcomes. J Neuroophthalmol. 2013;33:4-8.

115. Stiebel-Kalish H, Serov I, Sella R, Chodick G, Snir M. Childhood overweight or obesity increases the risk of IIH recurrence fivefold. Int J Obes (Lond). 2014;38:1475-7. 